\title{
Colecciones fotográficas y bibliografía sobre fotografía en el Ateneo de Madrid
}

\author{
María OLIVERA ZALDUA \\ Universidad Complutense de Madrid \\ molivera@pdi.ucm.es
}

Recibido: 09/04/2011

Aceptado: 10/05/2011

\section{RESUMEN}

El Ateneo Científico, Literario y Artístico de Madrid cuenta con importantes fondos fotográficos que no han sido analizados, tanto originales como revistas y libros. La fotografia ha estado siempre presente en la institución, bien como apoyo en las conferencias de socios e intelectuales, bien como documentos generados en su evolución. Damos a conocer las colecciones fotográficas del Ateneo de Madrid y elaboramos una bibliografía sobre fotografía con los fondos de su biblioteca, que consideramos fundamental para los investigadores.

Palabras clave: Ateneo de Madrid, bibliografía de fotografía, documentación, documentación fotográfica, fotografía

\section{Photographic collections and bibliography about photography at the Ateneo of Madrid}

\begin{abstract}
The Ateneo Cientifico, Literario y Artistico from Madrid has important photographic collections that have not been fully analysed, both original images and/or books and magazines. Photography has been constantly present at this institution, both, for associates meetings support as well as assets for intellectuals partners, including documents generated during their works evolution. We present photographic collections from Madrid's Ateneo and, we prepare a photographic bibliography using funds from Ateneo's Library, which we consider essential for researchers.

Key words:Ateneo de Madrid, Photography bibliography, Documents, Photographic documents, Photos, photographic collections
\end{abstract}

\section{INTRODUCCIÓN}

El Ateneo Científico, Literario y Artístico de Madrid fue creado en 1835 como defensor de las libertades de pensamiento y de expresión por el duque de Rivas, Salustiano Olózaga, Mesoneros Romanos, Alcalá Galiano, Francisco Fabre, Juan Miguel de los Ríos y Francisco López Olavarrieta. Su primera sede estuvo en el palacio de Abrantes (calle Mayor), luego en Carretas, después la Plaza del Ángel y Montera, hasta instalarse en 1884 en el número 21 de la calle Prado en un edificio modernista 
inaugurado por Cánovas del Castillo. Han formado parte de la Docta Casa presidentes de Gobierno, Premios Nobel, políticos e intelectuales. Entre 1923 y 1925, durante la dictadura de Primo de Rivera, se suspendieron todas las actividades, y durante la guerra civil permaneció abierto hasta la actualidad. Cuenta con archivo creado en 2007 y la biblioteca histórica de gran valor. Ambos departamentos conservan las colecciones fotográficas cuyos fondos se han ido incrementando en las sucesivas etapas con aportaciones particulares y colecciones destinadas a todas las actividades realizadas, incluyendo la donación, en febrero de 2010 de 16.000 tarjetas postales.

\section{OBJETIVOS, METODOLOGÍA Y FUENTES}

Es objeto de este artículo presentar y analizar las colecciones fotográficas que se conservan en la biblioteca y en el archivo, destacando los positivos de cristal del último tercio del siglo XIX. Se elabora asimismo una bibliografía con las publicaciones periódicas y monografías que se conservan en la biblioteca. La información se completa con los datos obtenidos en las entrevistas a las responsables de la biblioteca, Manuela Sánchez Quero, y del archivo, Clara Herrera Tejada.

Se han analizado tres catálogos de los positivos de cristal; dos de ellos con fichas descriptivas y un tercero dedicado a Manuel Azaña y a la primera guerra mundial, con 71 imágenes que el político y escritor utilizó en la conferencia que impartió en el Ateneo el 25 de enero de 1917, titulada "Impresiones de un viaje a Francia". Se han visualizado todas las fotografías de la página web y se han realizado búsquedas en la base de datos de la institución.

Las fuentes consultadas además de la página web del Ateneo (www.ateneodemadrid.es) han sido: El Diccionario Espasa fotografia (2002), El documento fotográfico: historia, usos y aplicaciones (2006) y La fotografia en España (2001). Sobre la institución destacamos como referencia: El Ateneo de Madrid (2006), Las estrellas del Ateneo (2010), El Ateneo de Madrid: sus orígenes, desenvolvimiento, representación y porvenir (2010), los artículos "El Ateneo, templo de cultura y democracia" (2008) y "El Ateneo de Madrid busca el esplendor perdido" (2005).

\section{LA COLECCIÓN FOTOGRÁFICA}

A finales del XIX, la fotografía se empezó a utilizar para difundir los trabajos artísticos como apoyo a las actividades académicas de los intelectuales en los grandes centros culturales de la época, donde completaban sus explicaciones con positivos de cristal (Sánchez Vigil, 2001). Este es el caso del Ateneo de Madrid, una de las primeras instituciones en incorporar la fotografía. Cánovas del Castillo, en carta fechada en 1890, le pedía a Arturo Mélida que incorporara todo tipo de fotografías a la conferencia que iba a pronunciar en el Ateneo, valiéndose del aparato de proyecciones que se 
encontraba en el salón de actos ${ }^{1}$. En 1906 Cánovas expuso en este recinto unas conclusiones sobre la importancia de la fotografía, indicando que las particularidades del mundo solo se podían conocer a través de la imagen, y proyectando varios cristales de paisajes y monumentos del mundo.

\subsection{LA COLECCIÓN DE PLACAS DE CRISTAL}

En la biblioteca del Ateneo de Madrid se conservan estos positivos, de un enorme valor por su antigüedad y contenido. Componen la colección 3600 unidades en tamaño de $85 \times 100 \mathrm{~mm}$, fechadas entre 1880 y 1920 . Los positivos fueron encontrados en un armario-fichero de madera, en la sala denominada "palomar". Actualmente se conservan en un archivador en el depósito del centro con las mejores condiciones para su uso. En el año 2000 se obtuvo una subvención del Ministerio de Cultura para su digitalización y catalogación, se reprodujeron con cámara digital en una mesa de luz, conservando su tamaño original, y se creó una base de datos en Access para su documentación con los siguientes campos: ID signatura, serie, tamaño, descripción, materia, persona, fotógrafo, lugar y notas. En el último apartado se fueron introduciendo los datos complementarios sobre las conferencias en las que se usaron.

Las materias obtenidas en la identificación de la base de datos fueron:

$\begin{array}{lll}\text { Animales } & \text { Escultura } & \text { Orfebrería } \\ \text { Arqueología } & \text { Esmalte } & \text { Pintura } \\ \text { Arquitectura } & \text { Grabados } & \text { Plantas } \\ \text { Artesonado } & \text { Ilustración de libros } & \text { Primera Guerra Mundial } \\ \text { Astronomía } & \text { Imprenta } & \text { Relieve } \\ \text { Autógrafos } & \text { Jardines } & \text { Sillería de coro } \\ \text { Azulejos } & \text { Manuscritos } & \text { Tapices } \\ \text { Barcos } & \text { Mapas } & \text { Tauromaquia } \\ \text { Cañones } & \text { Medallas } & \text { Tipos populares } \\ \text { Castillos } & \text { Monedas } & \text { Vidrieras } \\ \text { Cerámica } & \text { Monumentos funerarios } & \text { Zoología } \\ \text { Construcciones } & \text { Mosaicos } & \\ \text { Dibujos } & \text { Muebles } & \end{array}$

Por la cantidad de originales y por el interés del contenido destacan los siguientes temas: Arqueología (egipcia, etrusca, griega micénica, popular, religiosa, romana); arquitectura; cerámica (etrusca, griega, ibérica, micénica); Escultura (egipcia, española, etrusca, francesa, griega, ibérica, precolombina, religiosa); Pintura (alemana, austriaca, española, flamenca, francesa, griega, holandesa, italiana, rupestre) y Numismática.

\footnotetext{
${ }^{1}$ Carta de Antonio Cánovas del Castillo a Arturo Mélida, 4 de marzo de 1890, Archivo del Ateneo de Madrid, sign. Antigua P-2-62
} 


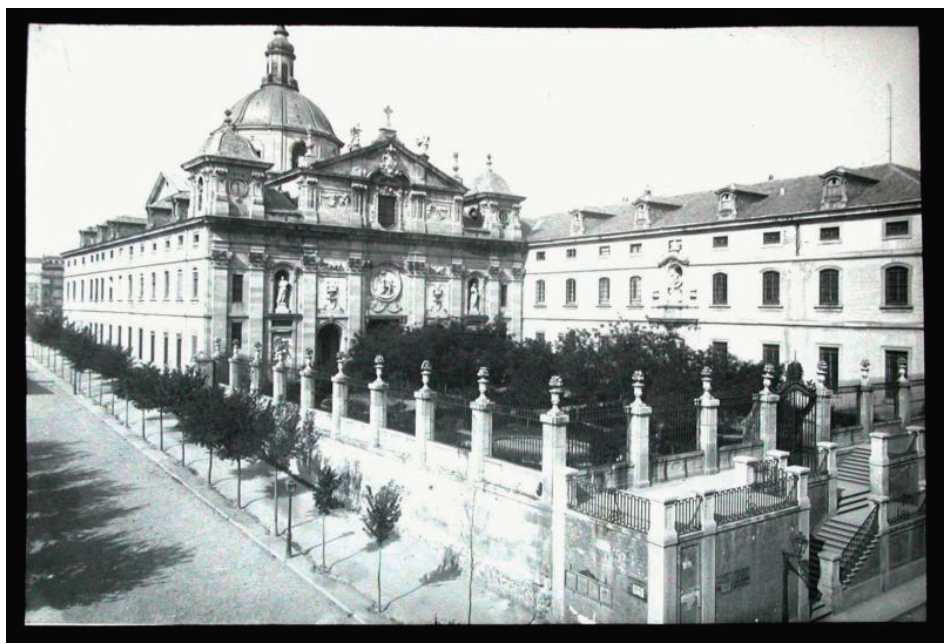

La iglesia de las Salesas Reales en Madrid, h. 1880. Foto: J. Laurent

En el año 2002 fueron incorporadas las imágenes a la biblioteca digital (www.ateneodemadrid.es) de la página web, con la descripción y un tesauro biográfico (escritores, pintores, escultores, arquitectos, políticos y reyes, santos, personajes de ficción, músicos y religiosos) y geográfico (España, Francia, Italia y otros países). De los 3600 cristales solo en 386 se indica el fotógrafo, destacando los 143 de Jean Laurent. El resto de fotógrafos figuran en la relación siguiente:

\begin{tabular}{|l|r|}
\hline AUTOR & FOTOS \\
\hline Fernández Balbuena & 10 \\
\hline Lacoste & 11 \\
\hline Lampérez y Romea, Vicente & 1 \\
\hline Laurent, Jean & 143 \\
\hline Levý et ses fils & 83 \\
\hline Mac-Pherson, José & 1 \\
\hline Mélida & 3 \\
\hline Moreno & 85 \\
\hline Winthuysen & 49 \\
\hline \multicolumn{2}{|c|}{ TOTAL } \\
\hline
\end{tabular}

\subsubsection{Los autores}

Los fotógrafos que realizaron las imágenes de las fotografías solo se han identificado en parte. Hemos realizado un breve apunte biográfico.

FERNÁNDEZ BALBUENA, GUSTAVO (Ribadavia 1888-1931)

Arquitecto y urbanista de gran relevancia. En 1918 fundó la revista Arquitectura y un año después accedió al puesto de Arquitecto Municipal del Ayuntamiento de Madrid. 
En este puesto diseñó el proyecto de un parque lineal a orillas del río Manzanares que se realizaría en 1931. En 1922 pronunció una conferencia en el Ateneo de Madrid titulada La arquitectura humilde de un pueblo del páramo leonés, que acompañó con los positivos de cristal y que se conservan en la institución.

LACOSTE, J.

Fotógrafo francés que se hizo cargo del estudio Laurent a partir de 1893, firmando las fotografías como Antigua Casa Laurent J Lacoste y Comp. Fue miembro de la Real Sociedad Fotográfica y su especialidad fue la reproducción de obras de arte. El Museo del Prado le encargó renovar su archivo fotográfico, involucrándose en su funcionamiento y editando un catálogo del mismo. Amplió considerablemente el fondo Laurent (véase).

\section{LAMPÉREZ Y ROMEA, VICENTE (Madrid 1861-1923)}

Arquitecto, restaurador e historiador del arte español, miembro de la Real Academia de la Historia. En 1900 publicó Arquitectura cristiana española, que se convirtió en una obra de referencia para los investigadores. Fue conservador de la catedral de Cuenca. En 1914 obtuvo el premio de Bellas Artes de Madrid con la obra La casa antigua española. El 28 de febrero de 1899 pronunció en el Ateneo la conferencia "Segovia, Toro y Burgos: observaciones sobre algunos de sus monumentos arquitectónicos de la Edad Media".

\section{LAURENT, JEAN (Garchizy 1816-Madrid 1886)}

Es uno de los grandes fotógrafos documentalistas. Llegó a España en 1843 y fue fotógrafo oficial de la reina Isabel II. Retrató a políticos, intelectuales y artistas, y recorrió todo el país documentando monumentos, obras públicas, obras de arte y tipos populares. En 1874 empezó a firmar Laurent \& Cia y hasta su muerte se dedicó a aumentar el fondo de negativos. En 1900 la empresa pasó a J. Lacoste y después a Ruiz Vernacci en 1927. Su fondo se conserva en el Instituto del Patrimonio Cultural de España.

\section{LEVÝ}

Bajo este nombre trabajaron numerosos fotógrafos que comenzaron su actividad en la década de los sesenta del siglo XIX. En los ochenta aumentaron su archivo con vistas de todo tipo. En 1874 la firma pasó a denominarse Levý \& Cie. Los profesionales del taller de Levy recorrieron Europa, África llegando a España en 1888. Siete años después cambiaron el nombre por Levý et ses fils, y a comienzos del siglo XX se dedicaron a la producción de tarjetas postales alcanzando en primer puesto de la producción francesa.

MACPHERSON, JOSÉ (Cádiz 1839-San Ildefonso 1902)

Geólogo que empezó su vocación en la serranía de Ronda. Miembro de la Sociedad Geológica de Francia, de la Sociedad Española de Historia Natural, de la Sociedad Geográfica de Madrid e impulsor de las ideas geológicas europeas. En 1885 leyó una 
conferencia en el Ateneo sobre los terremotos de Andalucía, ilustrados con unas fotografías de José García Ayola, uno de cuyos positivos en papel se conserva en la institución.

MÉLIDA, JosÉ RAMÓN (Madrid 1856-1933)

Es considerado el padre de la arqueología española. Novelista, historiador, crítico y arqueólogo. Estudió en el Ateneo, debatiendo con importantes personalidades como Juan Vilanova o José Villaamil. Fue director del Museo Arqueológico Nacional, uno de los primeros en fotografiar y documentar todas sus excavaciones, especialmente en Extremadura.

MORENO GARCÍA, MARIANO (Madrid 1865-1925)

Fotógrafo especialista en monumentos y en obras de arte de los principales museos españoles. Empezó como aprendiz en el estudio de Jean Laurent y en 1907 formó parte de la Junta de Iconografía Nacional que le encargó retratar a los personajes públicos más relevantes de la época. En 1912 abrió su propia galería, colaboró con la Sociedad Española de Amigos del Arte, y años más tarde trabajó con el Comité de Reforma, Reconstrucción y Saneamiento de Madrid, fotografiando todos los monumentos dañados o destruidos para su posterior restauración. Su fondo se conserva en el Instituto del Patrimonio Cultural de España.

WINTHUYSEN, XABIER (Sevilla1874- Barcelona 1956)

Pintor y fotógrafo. Recibió clases de pintura en el Ateneo. Fue amigo de Juan Ramón Jiménez, Joaquín Sorolla y Antonio Machado, quienes le introdujeron en la Institución Libre de Enseñanza. La Junta de Ampliación de Estudios le encargó estudiar, documentar, fotografiar y remodelar los jardines históricos de España: Abadía (Cáceres), Aranjuez, La Granja, El Escorial, El Pardo, Casa de Campo, Moncloa, y Parador de Ciudad Rodrigo. En 1922 pronunció una conferencia en el Ateneo de Madrid sobre los jardines proyectando los positivos de cristal de la Real Fábrica de Paños de Brihuega.

\subsection{Otras colecciones}

El Ateneo cuenta con otras colecciones de gran valor. Recientemente se descubrieron 15 fotografías fechadas en 1952 que fueron encargadas por el Ministerio de Información y Turismo con motivos de unas obras donde se eliminaron las estrellas que adornaban la fachada, escaleras y techos de la casa, por considerarlos símbolos masónicos. A mediados de diciembre del 2010 se han realizado un ciclo de conferencias, y una exposición y una monografía a modo de catálogo para dar a conocer este hecho (Herrera, 2010). 


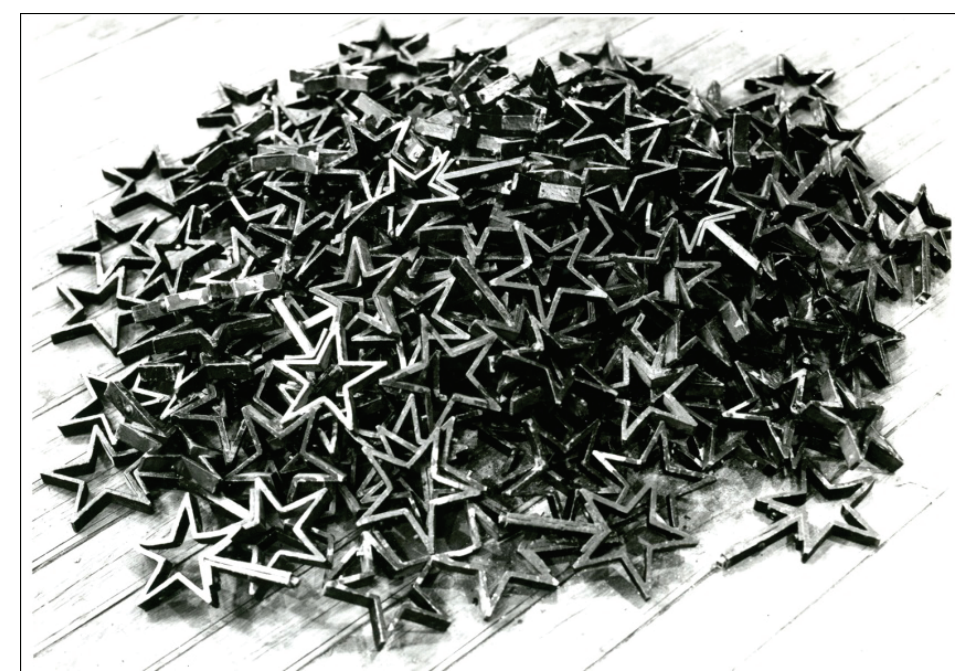

Estrellas retiradas de la escalera interior del Ateneo, 1952.

Foto Ministerio de Información y Turismo

La base de datos del Ateneo contiene 1532 imágenes de actos y presentaciones, la más antigua de 1981 y la última de 1998. A partir de ese año se han seguido fotografiando todos los acontecimientos pero no se han incluido en la web. El fotógrafo que cubrió los actos culturales hasta la guerra civil fue Alfonso Sánchez Portela, y su ayudante Gonzalo Casado siguió la actividad, entre 1940 y 1990.

Otro grupo documental lo forman fotografías tomadas entre los años cincuenta y ochenta, sobre exposiciones de artes, puestas en escenas teatrales, charlas y obras de mejora, donde aparecieron las imágenes de las estrellas mencionadas anteriormente.

Como complemento a esta documentación se ha investigado en instituciones oficiales para conocer otros fondos relacionados con el Ateneo, y en la búsqueda se localizaron 42 fotografías en el Archivo General de la Administración, fechados y firmados en los años treinta, tomadas por los grandes fotógrafos de la época: Videa, Cortés, Díaz Casariego, Campúa, Piortiz, Cortés y Alfonso; y la mayoría publicadas en las principales revistas de información: Crónica, La Esfera, Mundo Nuevo, Mundo Gráfico y Nuevo Mundo. 


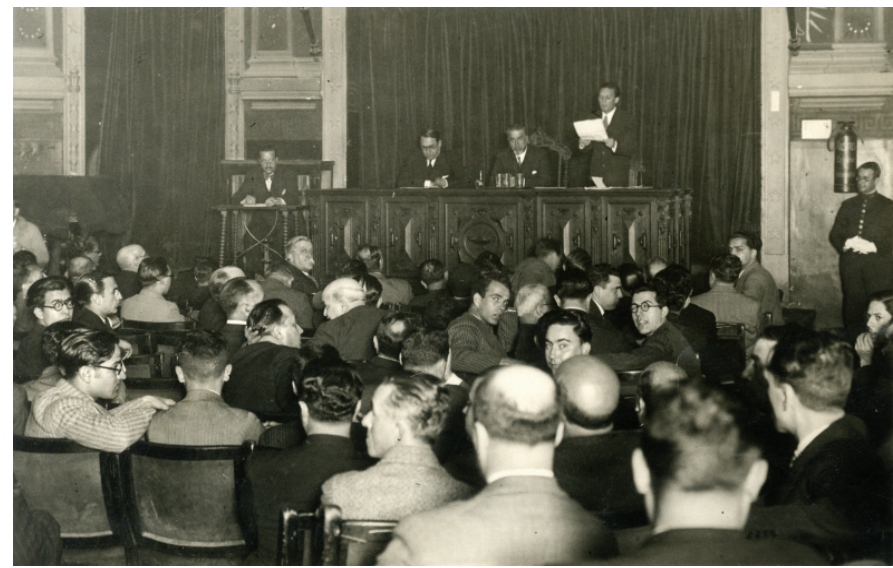

Debate sobre la presidencia del Ateneo de Manuel Azaña. Mundo Nuevo, 8 de abril de 1932. Foto Piortiz

En el fondo Alfonso del Archivo General de la Administración (Alfonso Sánchez Portela y Alfonso Sánchez García) también se conserva un importante número de imágenes relacionado con el Ateneo, si bien sería necesario un exhaustivo estudio.

Actualmente todas las imágenes, a excepción de los positivos en cristal y la base de datos, se conservan en el archivo. Las correspondientes a los actos culturales que de la institución se guardan en el departamento de comunicación. Junto a estas colecciones debemos mencionar por su interés las 16.000 tarjetas postales, en proceso de análisis y catalogación por la doctoranda Mariana López Hurtado de la Facultad de Ciencias de la Documentación de la Universidad Complutense de Madrid Mariana López. Fue donada en 2010 por el profesor Juan Miguel Sánchez Vigil.

\section{BIBLIOGRAFÍA SOBRE FOTOGRAFÍA EN LA BIBLIOTECA DEL ATENEO}

El catálogo de la biblioteca presenta cerca de doscientas monografías y revistas relacionadas con la fotografía, si bien tan solo un tercio (76 títulos) son libros y revistas directamente ajustadas a la materia. El libro más antiguo, titulado La photographie et la chimie de la lumière, está fechado en 1876, y el más reciente, editado por la Asociación de Comerciantes barrio del Las Letras, fue presentado en 2010 y se titula Exposición Concurso Fotográfico Internacional 2009.

\subsection{MONOGRAFÍAS}

259 Imágenes, fotografia actual en España (1983). Madrid: Círculo de Bellas Artes ADAMS, Ansel; Edward Weston, Josef KoudelKa (2009). Paisajes. Madrid: Público Alsina MunNe, H. (1954). Historia de la fotografía. Barcelona: Producciones Editoriales del Nordeste 
Altaminos López, Eduardo; Mónica CARABias Álvaro (2008). Artistas y fotógrafos: imágenes para una colección. Madrid: Museos de Madrid Arte Contemporáneo

American dreams (1987). Madrid: Ministerio de Cultura, Dirección General de Bellas Artes y Archivos, Centro Nacional de Exposiciones

American Photography. Two the secondo anual of American Editorial, advertising and poster, book, promotion and unpublisehd photography (1986). Nueva York: American photography

Años 60: Henri Cartier Bresson; Ellioot Erwitt, Bruno Barbey, Marc Riboud, Josef Koudelka, Los (2009). Madrid: Público

ARAMBURU Hermanos (1887). La fotografia al alcance de todos. Madrid: R. Nilasco

ARBUS, Diane (1986). Diane Arbus. Barcelona: Fundación La Caixa

Arte y vanguardia: Man Ray, Brassaï, Henri Cartier-Bresson, André Kertész, Philippe Halsman. Madrid: Público, 2009

CLIFFORD, Charles (1988). Vistas de las obras del Canal de Isabel II fotografiadas por Clifford. Madrid: Canal de Isabel II

BARTHES, Roland (1999). La cámara lúcida: nota sobre la fotografía. Barcelona: Paidós Ibérica

BOURDIEU, Pierre (1981). Un art moyen : essai sur les usages sociaux de la photographie. Paris: Les Editions de Minuit

Calle Mayor: fotografía urbana en América (2005). Madrid: La Fábrica

CARTIER-BRESSON, Henri (2003). Al gust de Cartier-Bresson. Barcelona: Fundació "La Caixa"

CASTILlo CÁCERes, Fernando; José María Moreno Martín; Elena MartíneZ OYARZÁBAL (2007). Hombres y barcos: la fotografía de la Marina española en el Museo Naval (1850-1935). Madrid: Ministerio de Defensa, Secretaría General Técnica

Colección de fotografia del Marqués de Cerralbo, La (2002). Madrid: Secretaría General Técnica, Subdirección General de Información y Publicaciones

Compromiso de la mirada: imágenes de la posguerra europea 1945-1962, El (1996). Barcelona: Fundación "La Caixa"

Cuatro Direcciones: fotografia contemporánea española 1970-1990 (1991). Barcelona:

Lunwerg

DÉRIBÉRÉ, Maurice (1953).La fotografia científica. Identificación. Estudio pericial de documentos y obras de arte. Policía judicial. Barcelona: Omega

Diaphanoramas en el Museo Romántico (1994). Madrid: Centro Nacional de Exposiciones y Promoción Artística: Museo Romántico

DOISNEAU, Robert (1993). La vie de famille. Paris: Hoëbeke

DOISNEAU, Robert [et al.] (2009). El mundo de la infancia. Madrid: Público

EFE-FLASH: 1987, un año en la vida de España (1988). Barcelona: Desarrollo Cultural

EFE-FLASH: 1992, un año en la vida de España (1993). Madrid: Fundación EFE EMANUEL, W.D. (1954). La Exakta : Jkine-Exakta I, II, Vy XV. Barcelona: Omega EMANUEL, W.D. (1954). La Karat y la Karomat: obtengamos los mejores resultados con todos los modelos. Barcelona: Omega 
EMANUEL, W.D.(196?). La Contaflex: cómo usar la nueva cámara réflex de un solo objetivo, con un solo objetivo con visor al nivel del ojo. Barcelona: Omega

España, diez miradas (2005). Madrid: Sociedad Estatal para Exposiciones Internacionales

Exposición Concurso Fotográfico: del 30 de enero al 22 de febrero 2009, Ateneo de Madrid (2009). Madrid: Asociación de Comerciantes Barrio de las Letras

Exposición Concurso Fotográfico Internacional 2009 (2010). Madrid: Asociación de Comerciantes Barrio de Las Letras

FABRE, Charles (1907). Traité encyclopédique de photographie. Toulouse: imp. Douladoure-Privat

Fondos fotográficos de la Fundación Cultural Banesto (1994) Madrid: Fundación Cultural Banesto

FONTENAY, Guillaume de (1912). La photographie et l'étude des phénomènes psychiques: abrégé de trois conférences données par l'auteur áa la Société Universelle d'Etudes Psychiques, en 1910 et 1911. Paris: Gauthier-Villars

FotoPres'01: exposición organizada por la Fundación "la Caixa" (2001). Barcelona: Fundación "la Caixa"

FotoPres'03: exposición organizada por la Fundación "la Caixa" (2003). Barcelona: Fundación "la Caixa"

FotoPres'07: exposición organizada por la Fundación "la Caixa" (2007). Barcelona: Fundación "la Caixa"

Fotografia en Cataluña 1900-1999 (2000). Madrid: Conde Duque

Fotografia en España en el siglo XIX, La (2003). Barcelona: Fundación "la Caixa" Fotografia en la colección del IVAM (2000). Valencia: IVAM Centre Julio González; Madrid: Aldeasa

Fotografia pictorialista en España, 1900-1936, la (1998). Barcelona: Fundación "la Caixa"

Fotografia sin cámara: collage y fotograma reciente en España, La. (1994). Madrid: Comunidad, Dirección General de Patrimonio Cultural.

Fotógrafos de la Escuela de Madrid: Obra 1950-1975 (1988). Madrid: Museo Español de Arte Contemporáneo

GARCÍA GARCÍA, José (1993). La fotografía astronómica. Madrid: Equipo Sirius

GONZÁLEZ PÉREZ, Antonio Jesús (2007). La mezquita de plata: un siglo de fotógrafos y fotografias de Córdoba (1840-1939). Córdoba: Fundación Provincial de Artes Plásticas "Rafael Botí"

Grandes metrópolis (2009). Madrid: Público

KeRTESZ, André [et al]. (2009). Formas y espacios. Madrid: Público

LEREBOURS, Nicolás Marie Paymal (1843). Traité de Photographie: derniers perfectionnements apportés au daguerreotype. Paris: N.-P. Lerebours; Londres: Claudet LEVENFELD, Rafael [et al.] (2007). Transformaciones: la España de los años veinte en los archivos fotográficos de Telefónica. Madrid: Fundación Telefónica: La Fábrica Madrid, ayer y hoy: la documentación fotográfica de la Dirección general de Bellas Artes y Archivos (1984). Madrid: Dirección General de Bellas Artes y Archivos 
Montero PÉREZ, Nemesio (1958). La fotografia en el campo de las Bellas Artes. Valladolid: Sever-Cuesta, imp

MUYBRIDGE, Eadweard (1893).Descriptive zoopraxography ot the science of animal locomotion made popular. Pensylvania: University of Pensylvania

El neorrealismo en la fotografía italiana (1999). Madrid: Centro Cultural del Conde Duque

NiCKLES, René (1893). Application de la photographie au dessin des cloisons des Ammonites. Lille: Imprimerie Lefebvre-Ducrocq -Photographie (2003). Paris: Ed. de la Réunion des musées nationaux

Nueva lente (1993). Madrid: Dirección General de Patrimonio Cultural: Fundación Caja de Madrid

Pasión por el deporte (2009). Madrid: Público

PETIT, A. Pierre (1883). La photographie artistique: paysages, architecture, groupes et Animaux. Paris: Gauthier-Villars, imprimeur-libraire

Photographie (2003). París: Ed. De la Reunion des musees nationaux

PIÑA, manuel (1986). Colección primavera-verano 1986.12 láminas con fotografías Premios del Certamen Nacional de Fotografía sobre Artes y Tradiciones Populares (1987). Madrid: Dirección General de Cooperación Cultural

PUÑTZ, John (1995). Le corps photographié. Paris: Flammarion

REBB, H. (1890). Etude sur l'hydroquinone: son application en photographie comme révélateur. Paris: Gauthier-Villars et fils imprimeurs-libraires

SANCHEZ VIGIL, Juan Miguel (1999). El universo de la fotografia: prensa, edición, documentación. Madrid: Espasa Calpe

SÁNCHEZ VIGIL, Juan Miguel (2002). Diccionario Espasa fotografia. Madrid: Espasa Calpe

SÁNCHEZ VIGIL, Juan Miguel (2002). La mirada ingenua: álbum de la infancia. Madrid: J.M. Sánchez Vigil

SÁNCHEZ VIGIL, Juan Miguel (2006). El documento fotográfico: historia, usos y apliaciones. Gijón: Trea

SÁNCHEZ VigIL, Juan Miguel (2006). Plátano versus piedra. Ávila: Concejalía de Cultura

SANCHEZ VIGIL, Juan Miguel [et al.] (2001). La fotografia en España: de los orígenes al siglo XXI. Madrid: Espasa Calpe

Siglo de las mujeres (2009). Madrid: Público

SOUGEZ, Maire-Loup (1985). Historia de la fotografia. Madrid: Cátedra

VALLVÉ, Manuel (1950). Tratado moderno de fotografia. Barcelona: José Montesó

VIDAL, León. (1884). Calcul des temps de pose et tables photométriques : pour l'appréciation des temps de pose nécessaires à l'impression des épreuves négatives à la chambre noire en raison de l'intensité de la lumière, de la distance focale, de la sensibilité des produits, du diamètre du diaphragme et du pouvoir réflecteur moyen des objets à reproduire. Paris: Gauthier-Villars

VOGEL, Hermann Wilhelm (1876). La photographie et la chimie de la lumière. Paris: Germer Baillière

WINDISCH, Hans (1958). Manual de fotografia moderna. Barcelona: Omega 


\subsection{Publicaciones periódicas}

Se conservan 6 revistas de gran valor documental, dos de ellas españolas. Es significativo que la revista más antigua proceda de Boston y que fuera incorporada a finales del siglo XIX cuando la actividad cultural del Ateneo era mayor.

Arte fotográfico. Fondos del año 1988

Fotografía, La. Antonio Cánovas director. Año $1 \mathrm{n}^{\circ} 1$ octubre 1901, año 12, n 147 diciembre 1913; $2^{\mathrm{a}}$ época año $1 \mathrm{n}^{\mathrm{o}}$ extraordinario, enero 1914, año $1 \mathrm{n} 12$ diciembre 1914, Madrid: Real Sociedad fotográfica 1901-1914. Fondos comprendidos entre 19011914

Photo-revue: jounal des photographer er des amateurs de photographies. Director Charles Mendel. Año 1, 1888-1966. París: s.n. Fondos: 1909-1913 (1914 falta agostooctubre) 1915-1918

Revista Documentación Fotográfica. Director G. Silvano Spinetti, año $1 \mathrm{n}^{\mathrm{0}} 1$ octubre 1953. Roma: Vecchioni y Guadagno, 1953. (1953 Falta el no 2) (1954)

Photo-era magazine: the American journal of photography. 1898-1920. Boston: The photo era publishing company, 1898-1920. Fondos 1909-12 (1913 falta enero), 1914(1915 falta octubre y noviembre), 1916-1917

Sombras: revista mensual de fotografía. Órgano oficial de la real sociedad fotográfica. Director Domingo de Luis, año I (junio 1944), no 93 (febrero 1954). Madrid: Real Sociedad Fotográfica, 1944-1954. Fondos: 1944-49 (1950)

\section{CONCLUSIONES}

Del estudio y análisis de los principales fondos y bibliografía del Ateneo, resultan las siguientes conclusiones:

1. Las instituciones privadas contribuyen al desarrollo y difusión e la fotografía en España. El caso del Ateneo es paradigmático.

2. Se constata el uso de la imagen como documento en las intervenciones de los intelectuales del Ateneo, así como su interés como con testimonio gráfico.

3. Las colecciones del Ateneo deberían estudiarse en profundidad para poner en valor su interés como patrimonio histórico. Un trabajo exhaustivo no solo ayudaría a conocer los orígenes de los fondos sino que aportaría datos para la investigación en varias líneas, sobre todo por el contenido.

4. Las colecciones fotográficas y la bibliografía sobre fotografía del Ateneo constituye un corpus documental básico para el estudio de la fotografía en España. 


\section{BIBLIOGRAFÍA}

Abellán, José Luis (2006). El Ateneo de Madrid. Madrid: Ediciones La Librería Ateneo de Madrid [recurso on-line]. www.ateneodemadrid.es [consulta: 28 de marzo 2011].

CASADO Rigalt, Daniel (2006). "José Ramón Mélida, un arqueólogo entre dos estilos", en Gerión, 24 (1), pp.371-404.

HerRera TeJADA, Clara (2010). "Las estrellas del Ateneo en 1952: el rastro de los documentos", en Las estrellas del Ateneo. Madrid: Ateneo de Madrid, pp. 9-18.

Herrera TejadA, Clara; Fernando Sígler Silvera; María Jesús SERRANo DE LA ROSA (2008). El Ateneo intervenido, 1939-1946. Madrid: Ateneo.

INTXAUSTI, Aurora (2005). "El Ateneo de Madrid busca el esplendor perdido", en El Pais, 12 de septiembre, p. 40.

LABRA, Rafael $\mathrm{M}^{\mathrm{a}}$ (2010). El Ateneo de Madrid: sus origenes, desenvolvimiento, representación y porvenir. Madrid: Ateneo.

MORAL, Ada del Moral (2008). "El Ateneo, templo de cultura y democracia", en Leer, $\mathrm{n}^{\circ} 191$, abril, pp.16-22.

OlIVERA ZALDUA, María (2010). "la fotografía, una (otra) forma de mostrar la historia", en Las estrellas del Ateneo. Madrid: Ateneo, pp.19-28.

SÁNCHEZ VIGIL, Juan Miguel (2007). Del daguerrotipo a la instamatic. Gijón: Trea.

SÁNCHEZ VIGIL, Juan Miguel, director (2001). La fotografía en España de los orígenes al siglo XXI, Summa Artis, vol.XLVIII. Madrid: Espasa Calpe.

SÁNCHEZ VigIL, Juan Miguel; María Olivera Zaldua (2009). La música callada de la fotografia. Miradas de Joaquín Turina. Madrid: Trama. 